Supplement of Biogeosciences, 16, 1883-1901, 2019

https://doi.org/10.5194/bg-16-1883-2019-supplement

(C) Author(s) 2019. This work is distributed under

the Creative Commons Attribution 4.0 License.

(c) (1)

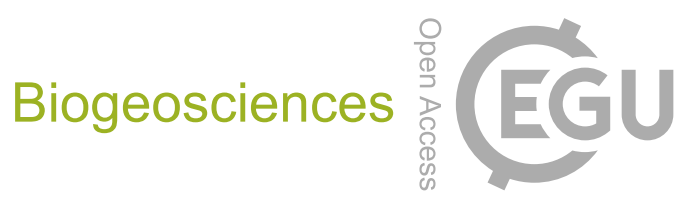

Supplement of

\title{
N : P stoichiometry and habitat effects on Mediterranean savanna sea- sonal root dynamics
}

Richard K. F. Nair et al.

Correspondence to: Richard K. F. Nair (rnair@bgc-jena.mpg.de)

The copyright of individual parts of the supplement might differ from the CC BY 4.0 License. 


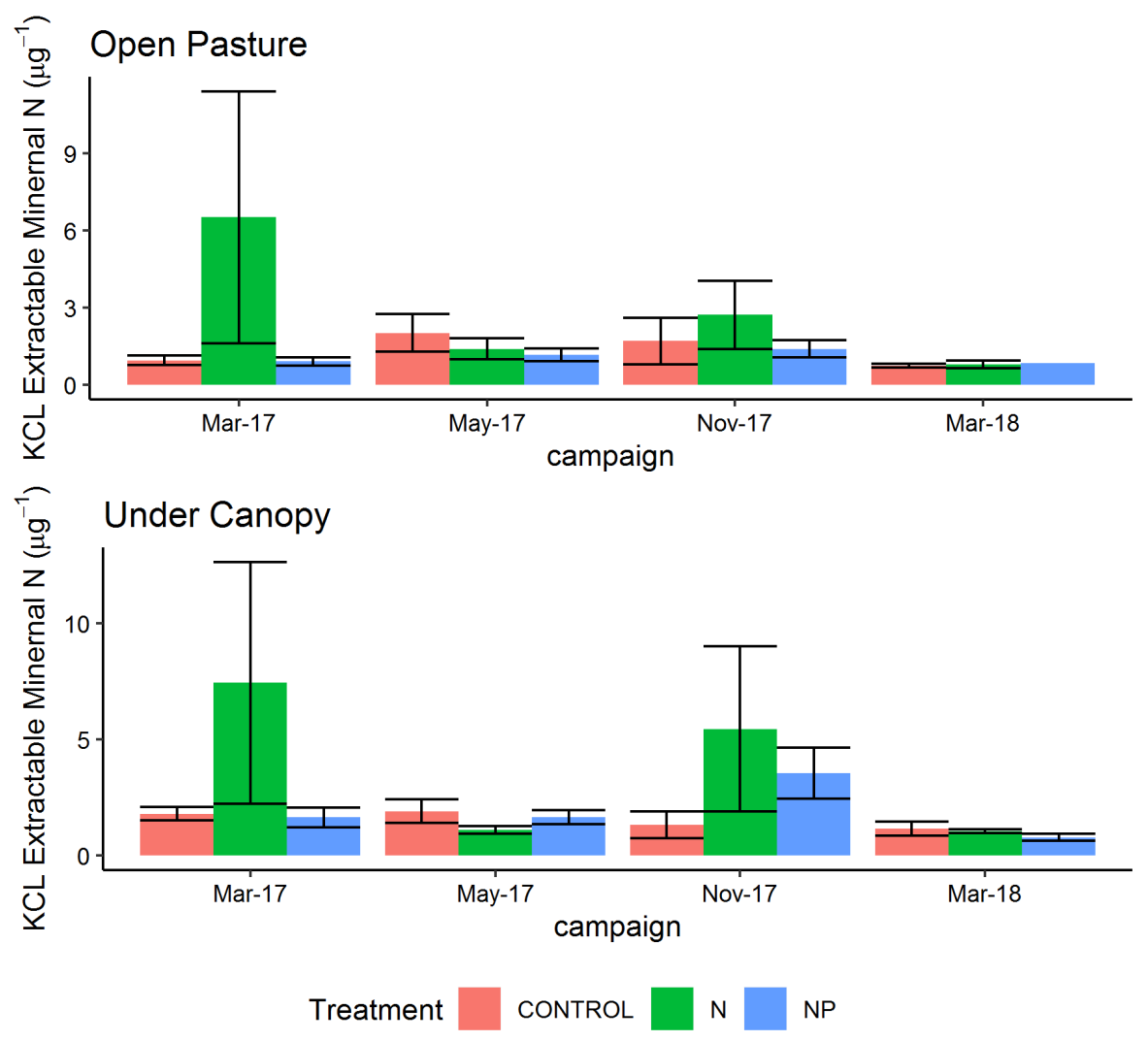

Figure S1. 2M-KCL extractable N in surface soil. There were no significant differences between treatments within habitat and campaign but a significant effect of habitat over the whole period of the experiment $(\mathrm{P}<0.05)$. Error bars show standard error of the mean

\section{Extractable $\mathbf{N}$ and $\mathbf{P}$}

In the main manuscript, we calculate 'available' NP ratios from soil extracts. Here we present data and a brief interpretation for the extractable fractions of $\mathrm{N}$ and $\mathrm{P}$ used to calculate these data. Statistical methodology follows the same method as in the main text.

$5 \quad$ Mean inorganic $\mathrm{N}$ availability were $2.37 \pm 3.8$ (sd.) $\mathrm{mg} \mathrm{g}^{-1}$ in under canopy microhabitats and $1.79 \pm 3.1 \mathrm{mg} \mathrm{g}^{-1}$ in pasture microhabitats (Figure S1). Overall there was a significant effect of habitat $(\mathrm{P}<0.05)$ on extractable inorganic $\mathrm{N}$ and a borderline non-significant $(\mathrm{P}=0.07)$ effect of $\mathrm{N}$ treatment. This was driven by very high $\mathrm{N}$ contents (up to $\left.22 \mathrm{mg} \mathrm{g}^{-1}\right)$ in some samples from the $\mathrm{N}$ treatment in March 2017 - later in the experiment these differences were much smaller and at individual dates there were not significant differences between treatments. Mineral N pools are driven by mineralization rates and biological uptake and for mineralization which so it is not clear if this declining difference and lack of NP treatment difference was due to changing $\mathrm{N}$ availability or depletion of this pool by uptake from plants in the NP treatment with a greater access to available P.

For phosphorus, there was a significant of the NP treatment $(\mathrm{P}<0.001)$ and habitat $(\mathrm{P}<0.001)$ on Olsen-P content (Figure $\mathrm{S} 2$ ). In the control and $\mathrm{N}$ treatment, mean extractable $\mathrm{P}$ was $3.00 \pm 2.78 \mu \mathrm{g} \mathrm{g}^{-1}$ in UC locations and $1.44 \pm 0.9 \mu \mathrm{g} \mathrm{g}^{-1}$ in tree covered locations. When $\mathrm{P}$ was added in the NP treatment, these phosphate-P concentrations were $7.03 \pm 5.6 \mu \mathrm{g} \mathrm{g}^{-1}$ in UC locations and $3.5 \pm 1.54 \mu \mathrm{g} \mathrm{g}^{-1}$ under trees. 

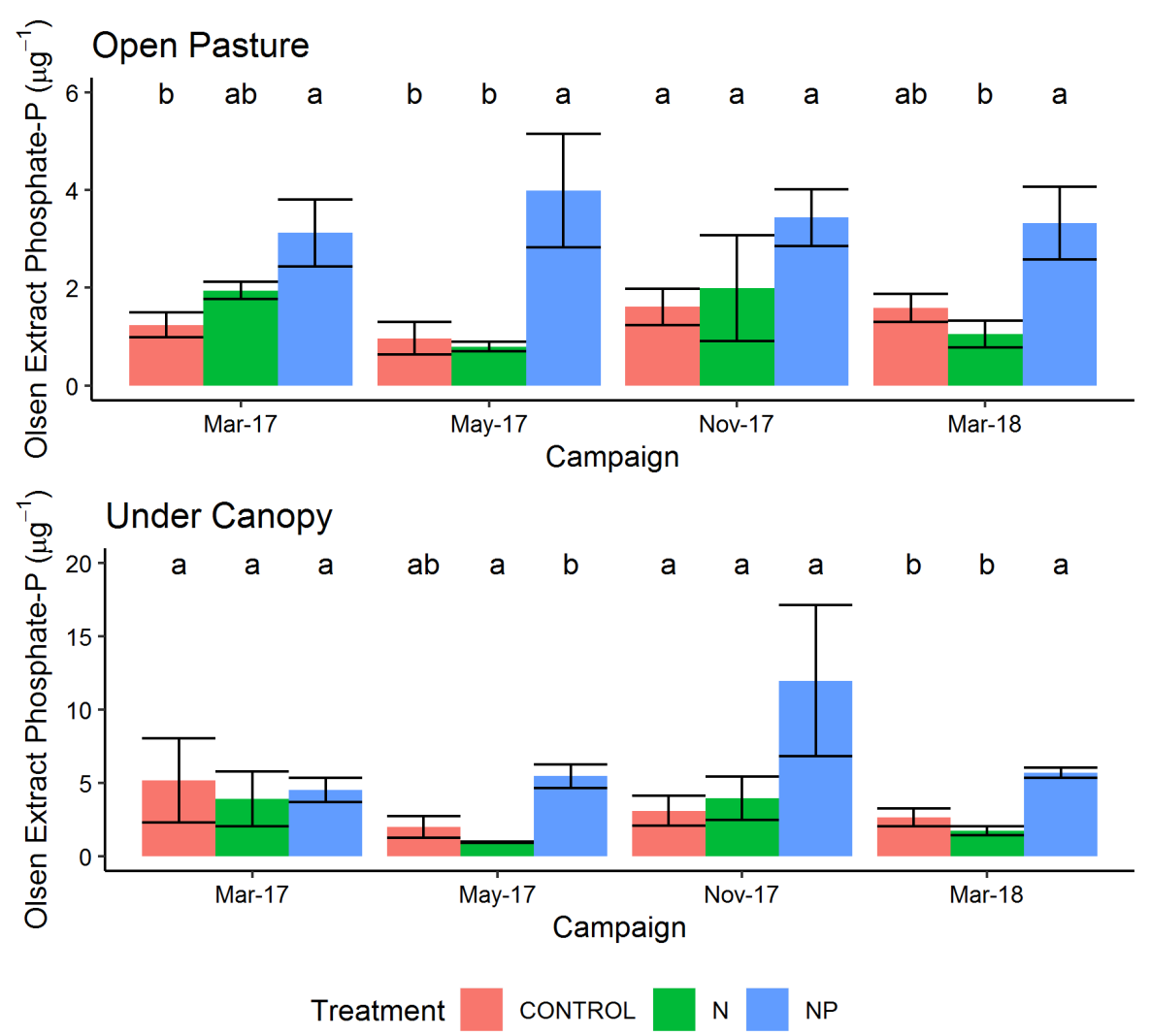

Figure S2. Olsen-extractable phosphate-P in surface soil. There were no significant differences before the treatment but during the period of the experiment, more P was found in the NP treatments and under canopy. Letters show Tukey HSD groupings within campaign-habitat combinations and errorbars show standard error of the mean. On this figure we also show pretreatment data, which is shown in figure 1 . in the main paper. 